ONDERZOEKSRAPPORT NR 9428

\author{
Legislative Procedures \\ in the European Community
}

by

Christophe CROMBEZ

$D / 1994 / 2376 / 30$ 


\title{
Legislative Procedures
}

\section{in the European Community}

\author{
Christophe Crombez
}

July 8, 1994

\begin{abstract}
This paper presents spatial models of three legislative procedures in the EC: the consultation, cooperation and assent procedures. The theory characterizes for each procedure the set of policies that can be adopted, the Commission proposal and the equilibrium EC policy as a function of the ideal policies of the countries, the Commission and the Parliament, and the location of the status quo. It yields comparative statements about EC policy and the institutions' powers under the three procedures, thus providing a framework for assessing arguments about the merits and demerits of existing EC institutions and proposals for institutional change.
\end{abstract}




\section{Introduction}

The institutions and legislative procedures of the European Communities (EC) have recently become the center of considerable controversy among political leaders and commentators. ${ }^{1}$ For some, European integration should be based on cooperation between independent, sovereign states, and EC policies should result from negotiations among national governments. Democracy is then best served by maintaining the powers of the individual national Parliaments. The European Commission and its Brussels bureaucracy demonstrate too much zeal in their regulatory activities. The Berlaymont, their headquarters, is compared with the Kremlin. As for the European Parliament, it is portrayed as a spendthrift and ridiculed for carrying out its activities on three different sites. It is considered powerless and therefore redundant.

Historically, the most prominent proponents of this intergovernmentalist vision have been General de Gaulle and Lady Thatcher, who in her famous "Bruges speech" on September 20, 1988 presented her views as follows:

I am the first to say that on many great issues the countries of Europe should try to speak with a single voice. I want to see them work more closely on the things we can do better together than alone. Europe is stronger when we do so, whether it be in trade, defense or in our relations with the rest of the world. But working more closely together does not

\footnotetext{
${ }^{1}$ The EC is one of the three pillars of the European Union established by the Treaty of Maastricht (1992). The other two pillars are the common foreign and security policy, and the cooperation in the fields of justice and home affairs. The EC consists of three communities: the European Coal and Steel Community (1951), the European Economic Community (1957) and the European Atomic Energy Community (1957). These are separate communities sharing the same institutional framework. The Treaty of Maastricht renamed the European Economic Community the European Community, thus creating more confusion, since the EC is usually referred to as the European Community. See Curtin (1993) for examples of confusing nomenclature in the Treaty of Maastricht.
} 
require power to be centralized in Brussels or decisions to be taken by an appointed bureaucracy.

For others, democratic accountability and institutional transparency are enhanced by ceding more power to supranational bodies, in particular to the Parliament. Since national governments defend their respective national interests rather than $\mathrm{EC}$ interests, cooperation between sovereign states and intergovernmental negotiations within the Council of Ministers lead to indecision, especially in view of the imminent enlargement of the EC which threatens further to complicate decision-making. Therefore, the Parliament should be transformed into a real legislature with the Commission as its executive. In his address to the Parliament on January 17, 1990 Mr. Delors, the Commission's President, expressed his supranationalist views as follows:

[T]he Commission should be turned into a proper executive... The executive would, of course, have to be answerable to the democratic institutions of the future federation... To deal with the democratic deficit... Parliament would have to be given more powers. ${ }^{2}$

The original EC Treaties concluded in the 1950s already reflected the conflict between intergovernmentalism and supranationalism, creating supranational institutions as the Commission and the Parliament while establishing the intergovernmental Council of Ministers as the principal legislative body. The following paragraphs focus on these institutions.

Table 1 presents the representation of the member countries in the EC institutions: the number of Commissioners, the number of votes in the Council and the number of seats in the Parliament. The table also provides population figures.

\footnotetext{
${ }^{2}$ The Parliament is directly elected but generally considered powerless. The Commission and the Council are considered powerful but are not directly elected. This situation is usually referred to as constituting a "democratic deficit."
} 
Table 1: Population and Representation in EC Institutions, July 1994.

\begin{tabular}{lrrrrrrrr} 
& \multicolumn{2}{c}{ Population } & \multicolumn{2}{c}{ Commission } & \multicolumn{2}{c}{ Council } & \multicolumn{2}{c}{ Parliament } \\
& mln. & $\%$ & members & $\%$ & votes & $\%$ & seats & $\%$ \\
\hline B & 10.0 & 2.9 & 1 & 5.9 & 5 & 6.6 & 25 & 4.4 \\
DK & 5.1 & 1.5 & 1 & 5.9 & 3 & 3.9 & 16 & 2.8 \\
G & 79.7 & 23.1 & 2 & 11.8 & 10 & 13.2 & 99 & 17.5 \\
GR & 10.2 & 3.0 & 1 & 5.9 & 5 & 6.6 & 25 & 4.4 \\
S & 39.0 & 11.3 & 2 & 11.8 & 8 & 10.5 & 64 & 11.3 \\
F & 56.5 & 16.4 & 2 & 11.8 & 10 & 13.2 & 87 & 15.3 \\
IRL & 3.5 & 1.0 & 1 & 5.9 & 3 & 3.9 & 15 & 2.6 \\
I & 57.7 & 16.7 & 2 & 11.8 & 10 & 13.2 & 87 & 15.3 \\
LUX & 0.4 & 0.1 & 1 & 5.9 & 2 & 2.6 & 6 & 1.1 \\
NL & 15.0 & 4.3 & 1 & 5.9 & 5 & 6.6 & 31 & 5.5 \\
P & 10.4 & 3.0 & 1 & 5.9 & 5 & 6.6 & 25 & 4.4 \\
UK & 57.5 & 16.7 & 2 & 11.8 & 10 & 13.2 & 87 & 15.3 \\
\hline Total & 345.0 & 100.0 & 17 & 100.0 & 76 & 100.0 & 567 & 100.0 \\
\hline \hline
\end{tabular}

$$
\begin{array}{ll}
\mathrm{B} & =\text { Belgium } \\
\mathrm{G} & =\text { Germany } \\
\mathrm{S} & =\text { Spain } \\
\mathrm{IRL} & =\text { Ireland } \\
\text { LUX } & =\text { Luxembourg } \\
\mathrm{P} & =\text { Portugal }
\end{array}
$$

$$
\begin{aligned}
\text { DK } & =\text { Denmark } \\
\mathrm{GR} & =\text { Greece } \\
\mathrm{F} & =\text { France } \\
\mathrm{I} & =\text { Italy } \\
\mathrm{NL} & =\text { the Netherlands } \\
\mathrm{UK} & =\text { the United Kingdom }
\end{aligned}
$$


The Commission consists of 17 members: 2 for each of the 5 largest member countries and 1 for each of the other countries. The Commissioners are appointed by common accord of the national governments, which means that unanimity in the Council is required. In practice each government chooses the Commissioner(s) from its country, and unless these choices meet resistance from another national government, they are subsequently appointed. Nonetheless, Commissioners are to be independent and are not allowed to seek or take instructions from their national governments or from any other body.

The Commission's main responsibility in the legislative process is as the principal initiator of legislative action. It makes policy proposals to the Council on its own initiative or at the Council's request. The Commission makes decisions by simple majority rule.

In the Council each country is represented by one government minister. Which ministers represent the member countries depends on the subject that is being discussed. As mentioned above, the Council is the EC's principal legislative body. It usually acts on a proposal by the Commission. Most of the important decisions require a qualified majority in the Council, and in some cases unanimity is required. ${ }^{3}$ Where a qualified majority is needed, the countries' votes are weighted to take into account the countries' populations, but the votes are not fully proportional to population. Under the qualified majority rule a proposal is approved if it receives at least 54 out of 76 votes $(71.05 \%)$. This means that support of a majority of the countries is needed (seven out of twelve). A blocking minority requires at least three countries.

The Parliament consists of 567 members, directly elected for five-year terms. The Parliament is not fully proportional, however, since the smaller countries are overrepresented. The Parliament uses simple majority rule but plays only a minor role in

\footnotetext{
${ }^{3}$ In EC terminology decision has a narrower meaning than it has in general. In this paper I use it in its broader meaning.
} 
the legislative process.

During the past three decades the tensions between the two visions, intergovernmentalism and supranationalism, have remained. They were most obvious during the 1960s when in several policy areas the EC Treaties provided for a gradual evolution from unanimity towards qualified majority voting in the Council. In practice unanimity was the rule until the Single European Act (SEA) took effect in 1987, since France had been unwilling to give up its veto during the 1960s. Even though the SEA restored the qualified majority rule, the Council usually still tries to reach a consensus.

The SEA also introduced two new legislative procedures granting the Parliament more power. Before the SEA most important decisions in the EC were taken under the consultation procedure, which was introduced by the original EC Treaties in the 1950s. Under this procedure the Council makes a decision on a proposal from the Commission, after receiving an opinion from the Parliament. Approval of the proposal by the Council requires a qualified majority, but the Council needs unanimity to amend the Commission proposal. The Parliament's opinion is not binding, so the Parliament can only delay legislation by not formulating an opinion. Currently, the consultation procedure accounts for about 75 percent of the legislation that passes through Parliament (199 opinions in 1993).

The SEA introduced two new procedures, the cooperation procedure and the assent procedure. These procedures essentially add additional stages to the consultation procedure. The Council decision - referred to as the common position - is sent back to the Parliament for a second reading. Under the cooperation procedure the Parliament can accept, amend or reject the common position. If the Parliament accepts the common position, the act is adopted. A rejection by the Parliament can be overturned only by a unanimous Council. An amended common position must be reexamined by the Commission which can accept or reject the amendments. The common position 
with the accepted amendments is then sent back to the Council, which can accept the reexamined proposal by a qualified majority. Approval of amendments requires unanimity. Under the assent procedure decisions require unanimity in the Council, and a rejection by the Parliament cannot be overturned. The Parliament, however, cannot amend a Council decision. The cooperation procedure accounts for about one fifth of the legislation that passes through Parliament (50 first readings in 1993); the assent procedure accounts for very little legislation (8 cases in 1993).

The Treaty of Maastricht (1992) introduced a fourth legislative procedure, the co-decision procedure. Under this procedure, adoption of an act requires approval by the Council and the Parliament. If the Council and the Parliament approve different texts, a Conciliation Committee, consisting of representatives of the Council and the Parliament, is convened to find a compromise. The treaty also gives the Parliament an important role in the nomination of the Commission and grants the Parliament the right to request proposals from the Commission. Nonetheless it keeps new policy areas, such as the common foreign and security policy, outside the institutional framework of the EC. In those areas the Parliament has no role, and decisions are based on intergovernmental negotiations. Since the treaty was not ratified until October 1993, the co-decision procedure has only recently been applied. In this paper I focus on the other three legislative procedures. The co-decision procedure and the Treaty of Maastricht are analyzed by Crombez (1994).

The institutions and legislative procedures of the EC have received considerable attention from academic scholars. The literature includes positive as well as normative work, but most is exclusively descriptive. Lasok (1991), Nugent (1991) and Peters (1992) provide a detailed description of the institutions. Others have focused on the procedures introduced by the SEA and their implications.

Bieber et al. (1986) claim that the SEA did not substantially increase the Parliament's powers. The assent procedure gives the Parliament a legislative veto, but only 
on a very small number of issues. The cooperation procedure also allows a legislative veto, but the Council can overturn the veto with a unanimous vote. Edward (1987) notes that although the SEA restored the qualified majority rule, the political reality is that "there is a limit beyond which the majority cannot go in imposing their will on the minority."

Bieber (1988) discusses a number of problems and ambiguities in the cooperation procedure and concludes that the differences in legislative procedures, while giving more power to the Parliament, complicate the EC's institutional structures. Fitzmaurice (1988) points out that the Commission's greatest fear is that the new procedures lead to indecision, i.e. an inability to act, if the Parliament and the Council are unable to agree. He also claims that the principal effect of the Parliament's second reading under the cooperation procedure is the growing influence of the Parliament during the earlier stages of the procedures.

Bogdanor (1989) notes that the cooperation procedure "vastly strengthens the power of the Commission when it is working together with Parliament." Corbett (1989) finds the consequences of the cooperation procedure to be ambiguous. A Parliament amendment rejected by the Council in the first reading does not seem likely to be more successful in the second reading, although an alliance of the Parliament and the Commission can "put a lot of pressure on the Council." Moreover, the Parliament will not be inclined to use its right to reject a common position, since usually it wants to accelerate integration rather than slow it down. Nonetheless one single ally in the Council can strengthen the Parliament's bargaining position. Lenaerts (1991) views the Commission's right to reject the Parliament's amendments at the second reading as the major weakness of the cooperation procedure.

Tsebelis (1992) presents a formal model of the cooperation procedure, which to my knowledge is the only such model of any of the legislative procedures in the literature. He focuses exclusively on the Parliament's second reading and the subsequent stages 
in the procedure, and concludes that the Parliament has acquired considerable power as a "conditional agenda-setter."

Surprisingly, no attempt has been made thus far to compare the legislative procedures with one another within a formal model. Herein lies the main contribution of this paper. The paper introduces spatial models of the consultation, cooperation and assent procedures. Countries and institutions are assumed to have Euclidean preferences over a unidimensional policy space and decide on an EC policy in a sequential game. The theory characterizes for each procedure the set of policies that can be adopted, the proposal the Commission makes, and the equilibrium EC policy as a function of the ideal policies of the countries, the Commission and the Parliament, and the location of the status quo. It yields comparative statements about EC policy and institutional powers under the three procedures.

The approach is positive rather than normative. The purpose is rigorously and consistently to analyze the three procedures, thus providing a framework for assessing claims concerning the workings of the EC institutions and procedures, and arguments over the future direction institutional change should take. No attempt is made to determine what the best procedure is, nor is it my intention to enter the debate on institutional change. The framework advanced in this paper is also used by Crombez (1994) to analyze the co-decision procedure.

In the next section I introduce the models. In the subsequent three sections I characterize the equilibrium policies under the three procedures and discuss the results. The sixth section presents the conclusions, and the equilibria are derived in the appendix. Indecision and a powerful Commission are shown to be important characteristics of all three legislative procedures considered. Indecision is, however, not caused by the intergovernmental nature of the principal legislative body, as claimed by supranationalists. Neither do the Commission's powers result from the supranational character of the Commission, as claimed by intergovernmentalists. Rather, 
both indecision and the Commission's powers result from the institutional requirements for adoption of legislation combined with the heterogeneity of countries' and institutions' preferences. Introduction of simple majority rule in the Council would reduce indecision and eliminate the Commission's powers. Under the new procedures, the Parliament has acquired veto-power. As a result, indecision has increased and the powers of the Commission have been reduced.

\section{The Models}

The policy space is assumed to be unidimensional. In reality, policy issues naturally involve more than one dimension. Distributive policies, for example, typically encompass as many dimensions as there are countries. Nonetheless, unidimensional models have their merits, especially for the study of universal, or collective goods, policies. Unidimensional models are analytically more tractable and allow for a more transparent exposition. Moreover, the EC does not adopt omnibus legislation and its institutions use germaneness rules. Commission proposals thus concern one or more specific policy areas, and the Council and the Parliament consider only related amendments. Therefore, the assumption of unidimensionality in models of EC policy making is more realistic than in similar models of the United States government. Finally, the non-existence of equilibria, typical of multidimensional social choice models, would not occur in multidimensional extensions of the models in this paper. Each procedure starts with a policy proposal from the Commission. The subsequent steps in the procedures determine the sets of policies that can be adopted. These sets of policies are non-empty, although they may in some cases include only the status quo. The Commission proposes the policy it prefers most among the policies that can be adopted, and this policy becomes EC policy, whether in the uni- or multidimensional setting. In short, the choice of unidimensional models is not innocuous, but neither 
is it grossly unrealistic or severely limiting.

Countries are assumed to have Euclidean preferences over the EC policy $p$, with ideal policy $\hat{p}_{i}$ for country $i{ }^{4}$ Country $i$ 's utility $V_{i}$ can then be represented as:

$$
V_{i}=-\left(\hat{p}_{i}-p\right)^{2}
$$

I order the countries such that country 1 has the lowest, and country $n$ the highest ideal policy: $\hat{p}_{1}<\hat{p}_{2}<\ldots<\hat{p}_{n}{ }^{5}$ The utility functions of the Commissioners and the Members of the European Parliament (MEPs) are also assumed to be Euclidean.

The internal decision-making processes within the Commission and the Parliament have the following properties: (1) the policy space is unidimensional, (2) Commissioners and MEPs have Euclidean preferences, (3) simple majority rule is used, and (4) there are no restrictions on amendments. As a consequence, the Commission and the Parliament can be treated as unitary actors with ideal policies equal to their median voters' ideal policies, $\hat{p}_{c}$ and $\hat{p}_{p}$ respectively. ${ }^{6} 7$

The Council is not represented as a unitary actor because it does not use simple majority rule but instead uses qualified majority rule or unanimity. Nonetheless, the analysis can be simplified by focusing on the countries that are pivotal under qualified majority rule and under unanimity rule.

Suppose the Council is comparing a proposed EC policy $p$ to the status quo $q$. For simplicity, the status quo is assumed to be equal to zero. A positive policy then represents a move to the right, a negative policy represents a move to the left. Since its

\footnotetext{
${ }^{4}$ The analysis can be extended to other types of single-peaked preferences with similar conclusions, but with different countries being pivotal in the Council. If preferences are not single-peaked, the conclusions depend on the entire configuration of preferences.

${ }^{5}$ I assume for simplicity that no two countries have identical ideal policies.

${ }^{6}$ In other words Black's median voter theorem applies (Black 1958).

${ }^{7}$ In multidimensional extensions of the models, there might not be an equilibrium if the Commission and the Parliament are not considered as unitary actors. In that case, cycling could occur.
} 
preferences are Euclidean, a country votes in favor of $p$ if $p$ is closer to that country's ideal policy than is the status quo. For country $i$ with a positive ideal policy, this condition is: $p \in A_{i}=\left[0,2 \hat{p}_{i}\right]$, where the set $A_{i}$ is country $i$ 's acceptance set. A similar condition holds for a country with a negative ideal policy. ${ }^{8}$

The acceptance sets of the countries are increasing in the distance between their ideal policies and the status quo. Thus, a positive policy that is unacceptable to country $n$, the country with the highest ideal policy, is unacceptable to all countries. In general, a positive policy is not acceptable to country $i$, if it is not acceptable to country $j>i$.

Let $v_{i}$ denote the number of votes country $i$ has in the Council, and let $n_{q}$ denote the number of votes required for a qualified majority in the Council. ${ }^{9}$ Then the country $a$ that is pivotal for a positive policy under the qualified majority rule fulfills the following two conditions. First, the coalition of country $a$ and all countries that have higher ideal policies constitutes a qualified majority. Second, this coalition does not have a qualified majority without country $a$. Therefore:

$$
\sum_{i=a+1}^{n} v_{i}<n_{q} \leq \sum_{i=a}^{n} v_{i}
$$

This condition states that country $a$ and the countries with higher ideal policies have at least $n_{q}$ votes in the Council and that this condition does not hold for the country with the next higher ideal policy. Analogously, the country $b$ that is pivotal for approval of a negative policy under the qualified majority rule can be characterized

\footnotetext{
${ }^{8}$ If $p=0$ or $p=2 \hat{p}_{i}$ country $i$ is indifferent between $p$ and the status quo. For simplicity I assume country $i$ then votes in favor of $p$. For a country $i$ with $\hat{p}_{i}=0$ the acceptance set $A_{i}$ is equal to the singleton $\{0\}$.

${ }^{9} \mathrm{~A}$ qualified majority requires 54 out of 76 votes. For the purposes of this theory, however, it is sufficient to assume that a qualified majority is larger than a simple majority.
} 
as follows: ${ }^{10}$

$$
\sum_{i=1}^{b-1} v_{i}<n_{q} \leq \sum_{i=1}^{b} v_{i} .
$$

Similar reasoning shows that the two extreme countries, country 1 and country $n$, are the pivotal countries under the unanimity rule.

The models incorporate complete information. The countries and institutions know each other's preferences, the location of the status quo, the impact of proposed policies, and the sequential structure of the models. They have perfect information on the actions taken in prior stages of the models. The models are analyzed in the following three subsections.

\subsection{The Consultation Procedure}

The model of the consultation procedure is shown in Figure 1. First, the Commission proposes a policy. Only the Commission can initiate the procedure, but it is required to make a proposal if the Council or the Parliament requests one. Thus the Commission has monopoly proposal power but it does not have gatekeeping power.

After the Commission makes a proposal, in the Council country 1 can propose an amendment to the Commission's proposal. For simplicity, I assume here that only country 1 can propose an amendment and that it can propose only one amendment. In reality, there are no limits on the number of amendments in the Council, and all countries can propose amendments. I will show in the appendix that this assumption does not affect the equilibrium Commission proposal.

If country 1 proposes an amendment, the Council votes whether or not to accept the amendment. The amendment is adopted if all countries accept it. If no amend-

\footnotetext{
${ }^{10}$ To obtain a qualified majority the proposal needs the support of at least 7 countries. If 2 of the largest 5 countries vote against, the support of 9 other countries is necessary. If 3 of the largest countries vote against, no qualified majority can be obtained. Hence, $\hat{p}_{a} \in\left\{\hat{p}_{3}, \hat{p}_{4}, \hat{p}_{5}, \hat{p}_{6}\right\}$ and $\hat{p}_{b} \in\left\{\hat{p}_{7}, \hat{p}_{8}, \hat{p}_{9}, \hat{p}_{10}\right\}$.
} 
Figure 1: The Consultation Procedure.

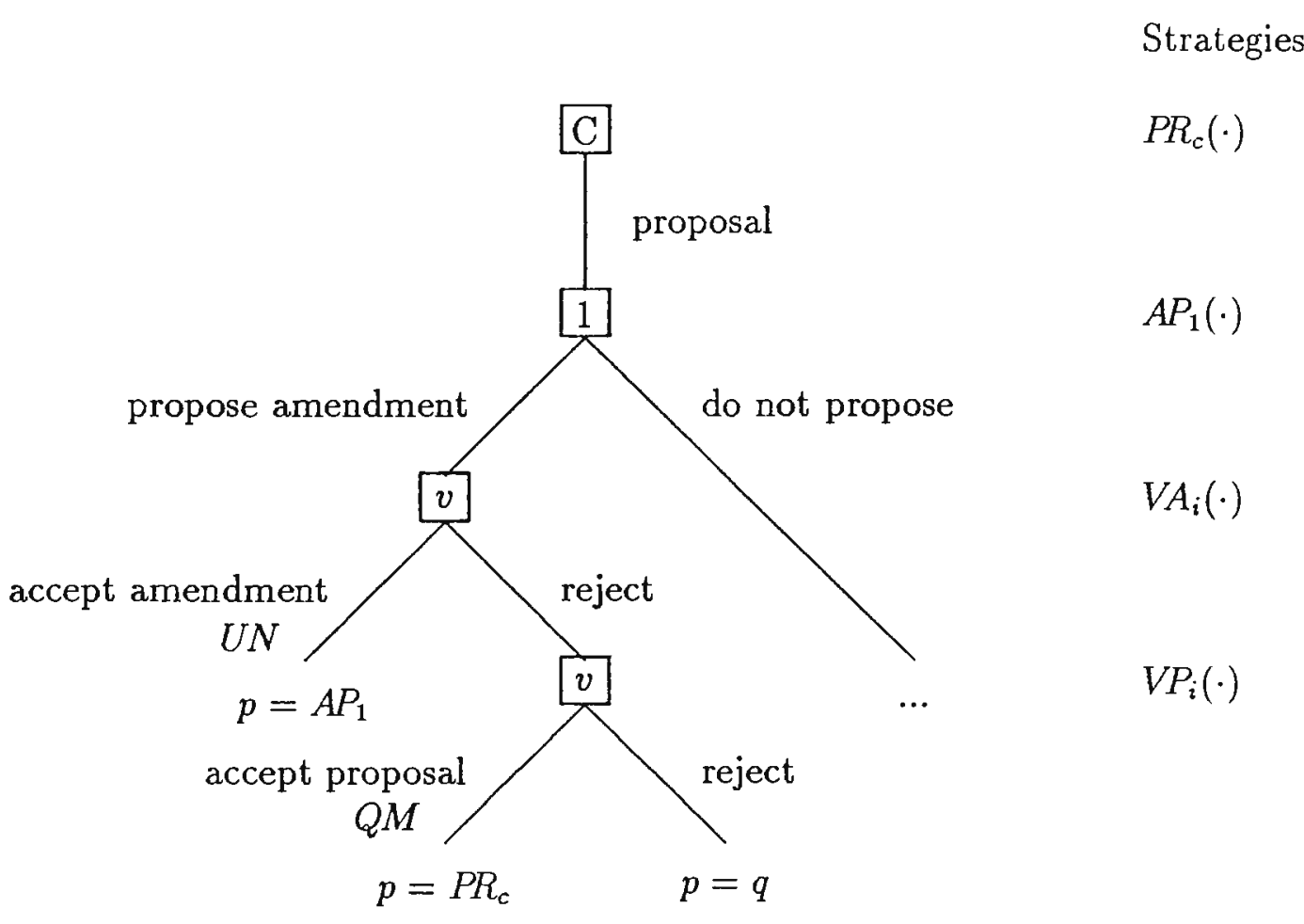

$$
\begin{array}{ll}
P R_{c}\left(\hat{p}_{c} ; \hat{p}_{1}, \ldots, \hat{p}_{n} ; \hat{p}_{p}\right) & =\text { Commission's proposal strategy } \\
A P_{1}\left(P R_{c}\right) & =\text { country } 1 \text { 's amendment strategy } \\
V A_{i}\left(P R_{c}, A P_{1}\right) & =\text { country } i \text { 's voting strategy on the amendment; } i=1, \ldots, n \\
V P_{i}\left(P R_{c} ; A P_{1} ; V A_{1}, \ldots, V A_{n}\right)= & \text { country } i \text { 's voting strategy on the Commission proposal; } \\
& \quad i=1, \ldots, n \\
C & =\text { Commission } \\
1 & =\text { country } 1 \\
v & =\text { vote in the Council } \\
U N & =\text { unanimity } \\
Q M & =\text { qualified majority }
\end{array}
$$


ment is made or the amendment is not adopted, the Council subsequently votes on the original Commission proposal. The proposal is adopted if a qualified majority in the Council supports it. If the proposal is not adopted, no policy is implemented and the status quo prevails.

In reality, the Parliament issues an opinion on the proposal before the Council considers it. Since its opinion is not binding, the Parliament has very little power. It can delay legislation by not issuing an opinion, and block other legislation if its opinion is ignored. Since I do not consider impatience and I focus on a single policy issue, I disregard the role of the Parliament in this procedure. In the broader context of the EC's legislative program, however, the Commission and the member countries might be more reluctant to ignore the Parliament's opinion. Similarly, they might prefer not to exclude a country too often from a qualified majority. In this respect, the model might underestimate the cohesiveness of the EC institutions somewhat.

\subsection{The Cooperation Procedure}

The model of the cooperation procedure is illustrated in Figure 2. The first four stages are like the consultation procedure. However, a Commission proposal as approved or amended by the Council - referred to as the common position - must go to the Parliament before it can become EC policy. The Parliament can accept or reject the common position. If the Parliament accepts the common position, it becomes EC policy. If the Parliament rejects the common position, it becomes EC policy only if the Council confirms it unanimously. To simplify the analysis, I assume for the moment that the Parliament does not amend the common position. I will show below that this assumption does not affect the equilibrium policy. Again, however, one could argue that in the broader context of the EC's legislative program the Commission and the member countries might be more reluctant to ignore the Parliament's amendments. 
Figure 2: The Cooperation Procedure.

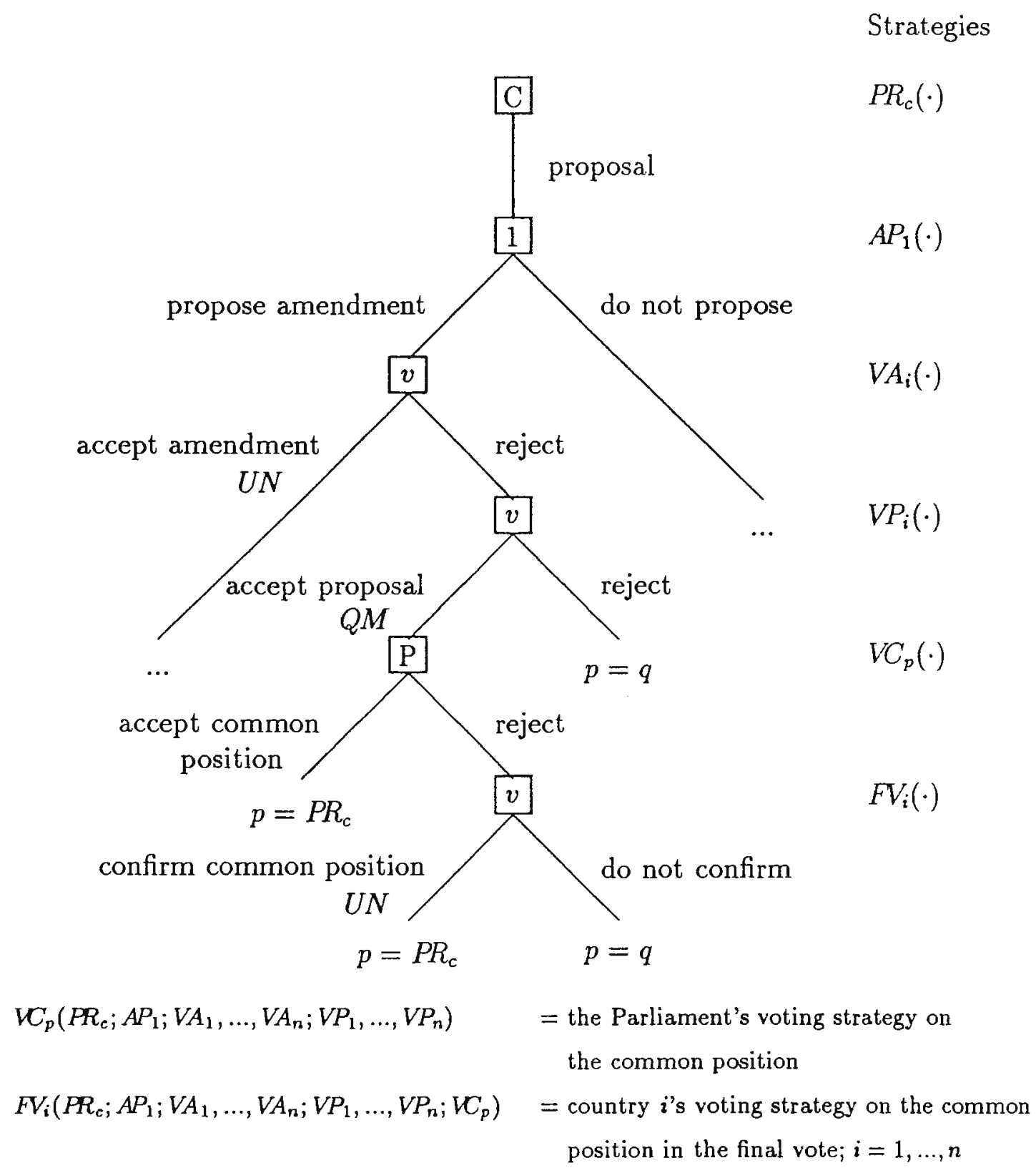




\subsection{The Assent Procedure}

The model of the assent procedure is like the cooperation procedure but with two differences. First, unanimity in the Council is required to adopt a common position in the fourth stage. ${ }^{11}$ Second, if the Parliament rejects the common position in the fifth stage the procedure ends and the status quo remains in effect. The Council is not allowed to confirm the common position by unanimity.

The equilibrium concept used in all three models is subgame perfect Nash. An equilibrium is then: an optimal proposal $P R_{c}^{*}\left(\hat{p}_{c} ; \hat{p}_{1}, \ldots, \hat{p}_{n} ; \hat{p}_{p}\right)$ for the Commission; an optimal amendment strategy $A P_{1}^{*}\left(P R_{c}\right)$ for country 1 ; optimal voting strategies $V A_{i}^{*}\left(P R_{c}, A P_{1}\right)$ for the $n$ countries on the amendment; optimal voting strategies $V P_{i}^{*}\left(P R_{c} ; A P_{1} ; V A_{1}, \ldots, V A_{n}\right)$ for the $n$ countries on the Commission proposal; under the cooperation and the assent procedures, an optimal voting strategy $V C_{p}^{\star}\left(P R_{c} ; A P_{1}\right.$; $\left.V A_{1}, \ldots, V A_{n} ; V P_{1}, \ldots, V P_{n}\right)$ for the Parliament on the common position; and, under the cooperation procedure, optimal confirmation strategies $F V_{i}^{*}\left(P R_{c} ; A P_{1} ; V A_{1}, \ldots, V A_{n}\right.$; $\left.V P_{1}, \ldots, V P_{n} ; V C_{p}\right)$ for the $n$ countries on the common position.

\section{The Consultation Procedure}

\subsection{Equilibrium}

The equilibrium under the consultation procedure is derived in Appendix A. Proposition 1 characterizes the set of proposals that can be adopted.

Proposition 1 Regardless of the relative locations of the status quo and the ideal policies, the set CS of proposals that can be adopted under the consultation procedure is the set of proposals that are preferred to the status quo by a qualified majority in the

\footnotetext{
${ }^{11}$ In the case of the assent procedure, the treaties do not use the term "common position." I do it merely to preserve the analogy with the cooperation procedure.
} 
Council and belong to the support of the countries' ideal policies: i.e., $C S=Q \cap S$, where $Q$ denotes the set of proposals that are preferred to the status quo by a qualified majority, and $S$ denotes the support of the countries' ideal policies. ${ }^{12}$

I use the configuration of ideal policies shown in Figure 3 to illustrate EC policy making under the three procedures. This configuration was chosen because it is not unlike the actual configuration in a left-right policy space. The Parliament has an ideal policy to the left of the countries that are pivotal under the qualified majority rule, whereas the Commission is located more to the right. ${ }^{13}$ In addition, this configuration of ideal policies clearly demonstrates the differences among the three procedures. In the literature, the relevant policy dimension is often considered to be an intergovernmental-supranational dimension rather than an economic left-right dimension (Garrett 1992, Tsebelis 1992). The Parliament and the Commission are then given a more supranationalist ideal policy than the countries. In Figure 3 the Parliament's ideal policy would then be located at the Commission's ideal policy.

In Figure 3 country $a$ has a positive ideal policy. A qualified majority then prefers a positive policy, and the set $Q$ of proposals that are preferred to the status quo by a qualified majority is equal to country $a$ 's acceptance set $A_{a}$. If the proposal belongs to this set, it is adopted in the last stage of the procedure as shown in Figure 1. Otherwise the status quo prevails. However, not all proposals $P R_{c} \in Q$ reach the last stage of the procedure. Consider a proposal that is preferred to the status quo by a qualified majority, but does not belong to the support of the countries' ideal policies,

\footnotetext{
${ }^{12}$ The support $S$ of the countries' ideal policies is equal to the set of policies $p$ such that no policy is preferred to $p$ by all countries.

${ }^{13}$ To locate the countries and institutions relative to one another I used data on party policy positions in a left-right policy space gathered by Laver and Hunt (1992). I assumed Commissioners and MEPs have the same policy positions as their national parties, and to obtain a country's policy position I averaged the policy positions of its governing parties .
} 
Figure 3: Policy Making under the Consultation Procedure.

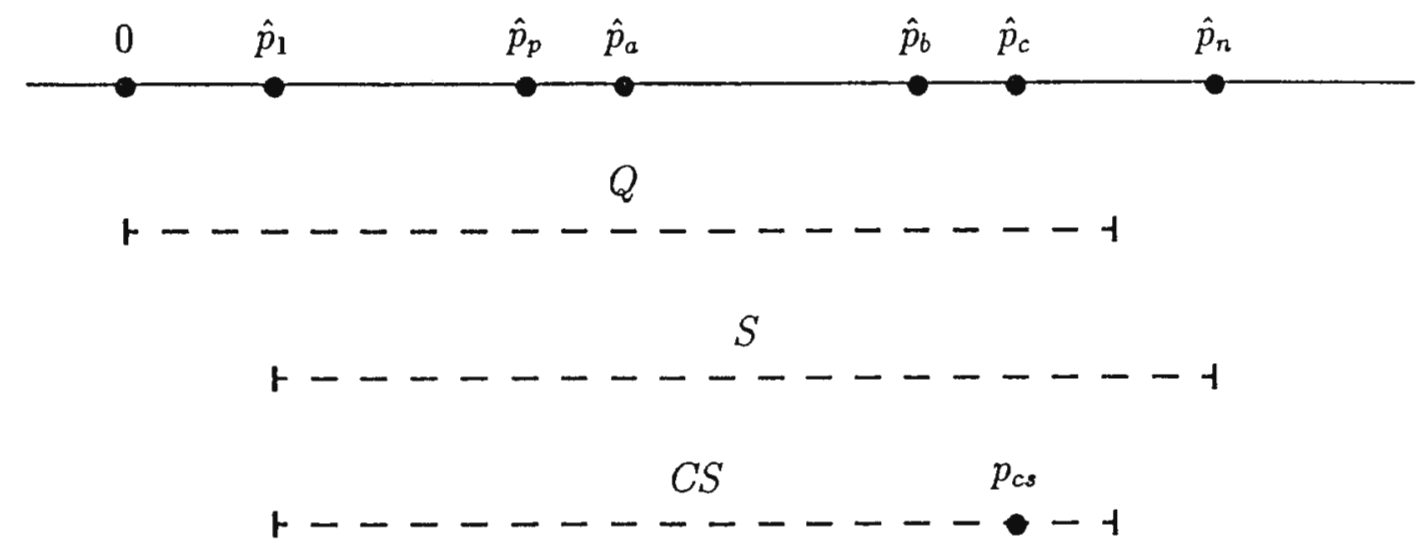

i.e. $P R_{c} \in Q \backslash S$. It is amended in the second stage of the procedure because all countries prefer a policy to the right of it. Only proposals that are preferred to the status quo by a qualified majority and belong to the support of the countries' ideal policies can be adopted.

The Commission makes the proposal $P R_{c} \in C S$ that is closest to its ideal policy. This proposal is not amended, obtains a qualified majority in the Council and becomes the EC policy $p_{c s}$ under the consultation procedure. In Figure 3 the Commission proposes its ideal policy. This policy is preferred to the status quo by a qualified majority in the Council and by the Commission. In general, it is possible however that the equilibrium policy is not preferred to the status quo by the Commission. If the Commission prefers the status quo to each country's ideal policy, it can at best obtain the closest country's ideal policy, since it has to make a proposal if the Council requests one. ${ }^{14}$ There are thus two possible minimal winning coalitions for

\footnotetext{
${ }^{14}$ The Commission does not prefer the equilibrium policy to the status quo if $C S \cap A_{c}=Q \cap S \cap$ $A_{c}=\emptyset$, where $A_{c}$ is the Commission's acceptance set and is defined analogously to the countries'
} 
Table 2: Minimal Winning Coalitions for EC Legislation.

\begin{tabular}{lll}
\hline \hline consultation & cooperation & assent \\
\hline C \& QM & C \& QM \& P & UN \& P \\
UN & UN & \\
\hline \hline
\end{tabular}

$$
\begin{aligned}
& \mathrm{C}=\text { Commission } \\
& \mathrm{QM}=\text { a qualified majority in the Council } \\
& \mathrm{UN}=\text { unanimity in the Council } \\
& \mathrm{P} \quad=\text { Parliament }
\end{aligned}
$$

adoption of legislation under the consultation procedure: (1) the Commission and a qualified majority in the Council, and (2) all countries. ${ }^{15}$ Table 2 illustrates the possible minimal winning coalitions under the three legislative procedures.

Figure 4 shows the equilibrium policy as a function of the location of the status quo relative to the ideal policies. The same configuration of ideal policies is used as in Figure 3. Five intervals can be distinguished for the equilibrium. In interval III the status quo prevails because there is no qualified majority in the Council to move either to the left or to the right. Country $a$ is pivotal for a move to the right, but its ideal policy is to the left of any policy in interval III. Similarly, country $b$ is pivotal for a move to the left, but prefers a policy to the right of any policy in interval III. In interval IV the status quo prevails as well although for different reasons. Country $b$ and thus a qualified majority in the Council want to move to the acceptance sets. Since $Q \cap S \neq \emptyset$ and $Q \cap A_{c} \neq \emptyset, \quad C S \cap A_{c}=\emptyset \Leftrightarrow S \cap A_{c}=\emptyset$.

${ }^{15} \mathrm{~A}$ coalition is a set of countries and institutions. It is winning if approval by all its members assures adoption of a proposal. A winning coalition that would no longer be winning if any member were to leave is a minimal winning coalition. 
left but the Commission prefers the status quo. Moreover, there is no unanimity in the Council for a move to the left, since country $n$ has an ideal policy to the right of any policy in interval IV. In interval II, $\left[2 \hat{p}_{a}-\hat{p}_{c}, \hat{p}_{a}\right)$, the Commission exercises agenda-setting powers without, however, obtaining its ideal policy. ${ }^{16}$ Country $a$ and thus a qualified majority in the Council want to move to the right and so does the Commission, but country a prefers the status quo to the Commission's ideal policy. The policy that makes country $a$ indifferent to the status quo then becomes EC policy. In intervals $I$ and $V$ the Commission's ideal policy is the equilibrium EC policy. In interval $I$ the Commission and a qualified majority both want a move to the right. In addition, a qualified majority prefers the Commission's ideal policy to the status quo. In interval $\mathrm{V}$ the Commission and a qualified majority both want a move to the left. The Commission manages to obtain its ideal policy because a qualified majority wants to move even further to the left but there is no unanimity for such a move. ${ }^{17}$

\subsection{Discussion}

The consultation procedure is a compromise between intergovernmentalism and supranationalism. On the one hand, decisions are taken through intergovernmental nego-

${ }^{16}$ The seminal paper on agenda-setting behavior is Romer and Rosenthal (1978).

${ }^{17}$ Depending on the location of the Commission's ideal policy relative to the pivotal countries, four other situations are possible. (1) The Commission's ideal policy is located between country a's ideal policy and country $b$ 's ideal policy. The Commission then has agenda-setting power in interval IV, $\left[\hat{p}_{b}, 2 \hat{p}_{b}-\hat{p}_{c}\right)$, because both country $b$ and the Commission want to move to the left. (2) The Commission prefers a policy to the right of all countries' ideal policies. In that case it cannot obtain its ideal policy in intervals I and $\mathrm{V},\left(-\infty, 2 \hat{p}_{a}-\hat{p}_{n}\right)$ and $\left[\hat{p}_{n}, \infty\right)$, and $\hat{p}_{n}$ then becomes EC policy. (3) The Commission's ideal policy is between country 1's ideal policy and country a's ideal policy. Then the equilibrium policies are analogous to the equilibrium policies in Figure 4. (4) The Commission's ideal policy is to the left of country 1's ideal policy. The equilibrium policies are then analogous to the equilibrium policies under (2). 
Figure 4: Equilibrium Policy under the Consultation Procedure.

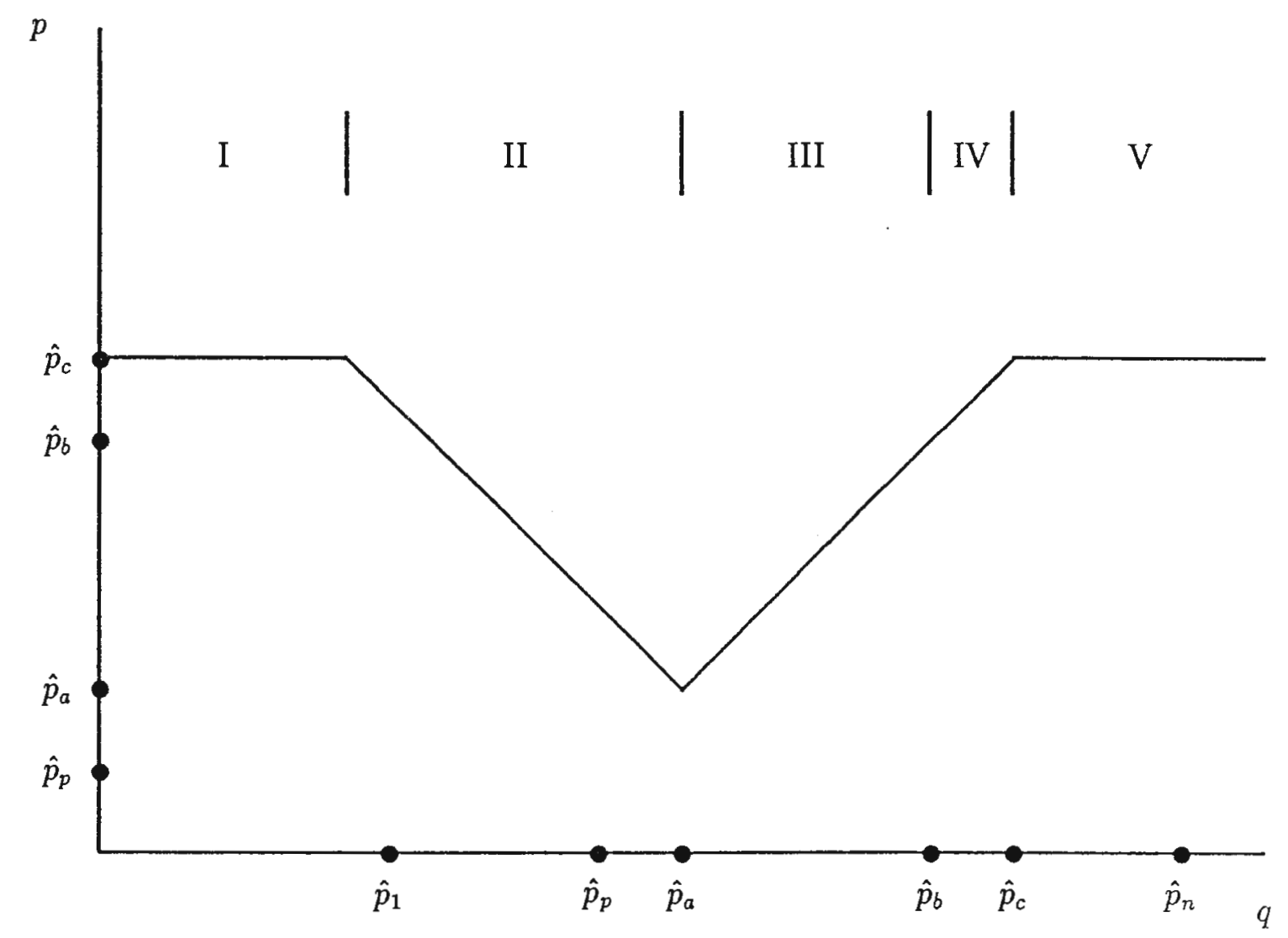


tiations in the Council. On the other hand, the proposal is made by the Commission and it only needs a qualified majority for approval. This subsection addresses two issues that arise in the debate between intergovernmentalists and supranationalists: (1) indecision, the propensity for status quos to remain unchanged, and (2) the Commission's powers, its ability to affect the equilibrium policy. ${ }^{18}$ The former has been identified by supranationalists as one of the shortcomings of intergovernmentalism. The latter is considered excessive by intergovernmentalists.

Under the consultation procedure the EC's ability to reach decisions is limited. Some status quos cannot be changed by equilibrium play of the game even though the Commission, the Parliament, and a majority of the member countries all want change. There are two situations in which this indecision occurs: (1) no qualified majority in the Council agrees on the direction of change, as in interval III in Figure 4; or (2) a qualified majority agrees but the Commission and some countries do not agree with the qualified majority, as in interval IV in Figure 4. This indecision can be considered an EC form of gridlock. Krehbiel (1993) studies gridlock in the United States government and concludes that it has nothing directly to do with partisanship but results from institutional features and the heterogeneity of preferences. Similarly, indecision under the consultation procedure is caused by the institutional requirements for the adoption of legislation, the qualified majority rule for adoption of proposals and the unanimity rule for adoption of amendments, combined with the heterogeneity of preferences within the Council and between the Council and the Commission. Contrary to the claims made by supranationalists the indecision is not directly caused by the intergovernmental nature of the principal legislative body. It would disappear if the Council were to make decisions by a simple majority. ${ }^{19}$ Note,

\footnotetext{
${ }^{18}$ Since preserving the status quo also represents a decision, one might prefer the term "stasis" to indecision.

${ }^{19}$ In a pure intergovernmental system, however, all decisions require unanimity in the Council. This
} 
however, that in multidimensional extensions of the model the use of simple majority rule in the Council could lead to the non-existence of equilibria.

The Commission plays an important role in the consultation procedure and at first glance it seems to have considerable powers. For extreme status quos it successfully proposes its ideal policy, as in intervals $\mathrm{I}$ and $\mathrm{V}$ in Figure $4 .^{20}$ For moderate status quos it exercises agenda-setting powers, as in interval II; it blocks a change that is preferred by a qualified majority, as in interval IV; or the status quo prevails because it does not have the support of a qualified majority to implement any policy change, as in interval III.

However, the Commission proposal is not implemented over the objections of the Council but is approved by a qualified majority. Two notions of power can be distinguished (Krehbiel 1988). Positive power is the ability of the Commission to change policy consistent with its preferences but contrary to the preferences of a qualified majority in the Council. Negative power is the ability of the Commission to maintain the status quo even though a qualified majority in the Council prefers to change it. The Commission thus does not have positive power. It is possible that countries with extreme ideal policies prefer the status quo to the Commission proposal. ${ }^{21}$ Nonetheless, it is not the supranational character of the proposer but the use of the qualified majority rule that, combined with the heterogeneity of preferences, gives rise to this possibility. If one of the countries were the proposer the possibility would remain. The possibility would be eliminated if unanimity were required for all

increases the indecision because it eliminates one of the two possible minimal winning coalitions.

${ }^{20}$ Note however that the Commission proposes the ideal policy of the closest country if all countries have a higher (lower) ideal policy than the Commission.

${ }^{21}$ Country $i$ such that $\hat{p}_{i}<\hat{p}_{a}$ or $\hat{p}_{i}>\hat{p}_{b}$ is considered a country with an extreme ideal policy. If a qualified majority wants to move to the right it is possible that countries that have ideal policies to the left of country a's ideal policy prefer the status quo to the equilibrium policy, depending on the Commission's ideal policy. Similar reasoning holds if a qualified majority wants to move to the left. 
decisions.

Moreover, there is no policy the Council unanimously prefers to the equilibrium policy. It is, however, possible that a qualified majority prefers a change. The Commission thus has negative power. Once more, this does not directly result from the supranational character of the proposer but from the use of the unanimity rule for amendments combined with the heterogeneity of preferences. A country with extreme preferences could also block a change preferred by a qualified majority if it were the proposer. Moreover, the consultation procedure does not differ from pure intergovernmentalism on this point, since under a pure intergovernmental system any change is blocked if the Council cannot agree unanimously.

The Commission thus has as much power as any proposer with the same preferences would have given the voting rules in the Council. It can propose any proposal that is preferred to the status quo by a qualified majority and belongs to the support of the countries' ideal policies. It can maintain the status quo even though a qualified majority in the Council prefers to change it. This negative power would be eliminated by the introduction of simple majority rule in the Council, for approval of proposals as well as amendments. This would be a move away from pure intergovernmentalism. With respect to the heterogeneity of preferences between the Council and the Commission it is worth noting that the Commission is appointed by the Council. If the Commission has extreme preferences, this is due to the appointment process rather than to the supranational character of the Commission. The appointment process is a good candidate for future research.

Indecision and the Commission's power are thus both caused by the use of the qualified majority rule for the adoption of proposals and the unanimity rule for the adoption of amendments combined with the heterogeneity of preferences. Indecision and the Commission's power would disappear if the Council used simple majority rule for proposals and amendments. 


\section{The Cooperation Procedure}

\subsection{Equilibrium}

The equilibrium under the cooperation procedure is derived in Appendix B. Proposition 2 characterizes the set of proposals that can be adopted.

Proposition 2 Regardless of the relative locations of the status quo and the ideal policies, the set CP of proposals that can be adopted under the cooperation procedure is the set of proposals that are preferred to the status quo either by a qualified majority in the Council and by the Parliament or by all countries, and that belong to the support of the countries' ideal policies: $C P=Q \cap\left(A_{p} \cup U\right) \cap S$, where $A_{p}$ is the Parliament's acceptance set, defined in the same way as a country's acceptance set, and $U$ is the set of proposals that are preferred to the status quo by all countries. The set CP is a subset of the set of proposals that can be adopted under the consultation procedure: $C P \subseteq C S$.

In Figure 5 policy making under the cooperation procedure is illustrated using the same configuration of ideal policies as in Figure 3. All countries have a positive ideal policy. The set $U$ of policies that are preferred to the status quo by all countries is thus country 1's acceptance set $A_{1}$. If the common position belongs to this set, it is confirmed in the last stage of the procedure as shown in Figure 2. The set of common positions that are approved by the Parliament in the fifth stage is the Parliament's acceptance set $A_{p}$. Since the Parliament prefers a policy to the right of country 1's ideal policy, the set of common positions that can become EC policy is thus the Parliament's acceptance set $A_{p}$. To become the common position a Commission proposal must belong to the set $Q$ of policies that are preferred to the status quo by a qualified majority, and to the support $S$ of the countries' ideal policies. 
Figure 5: Policy Making under the Cooperation Procedure.

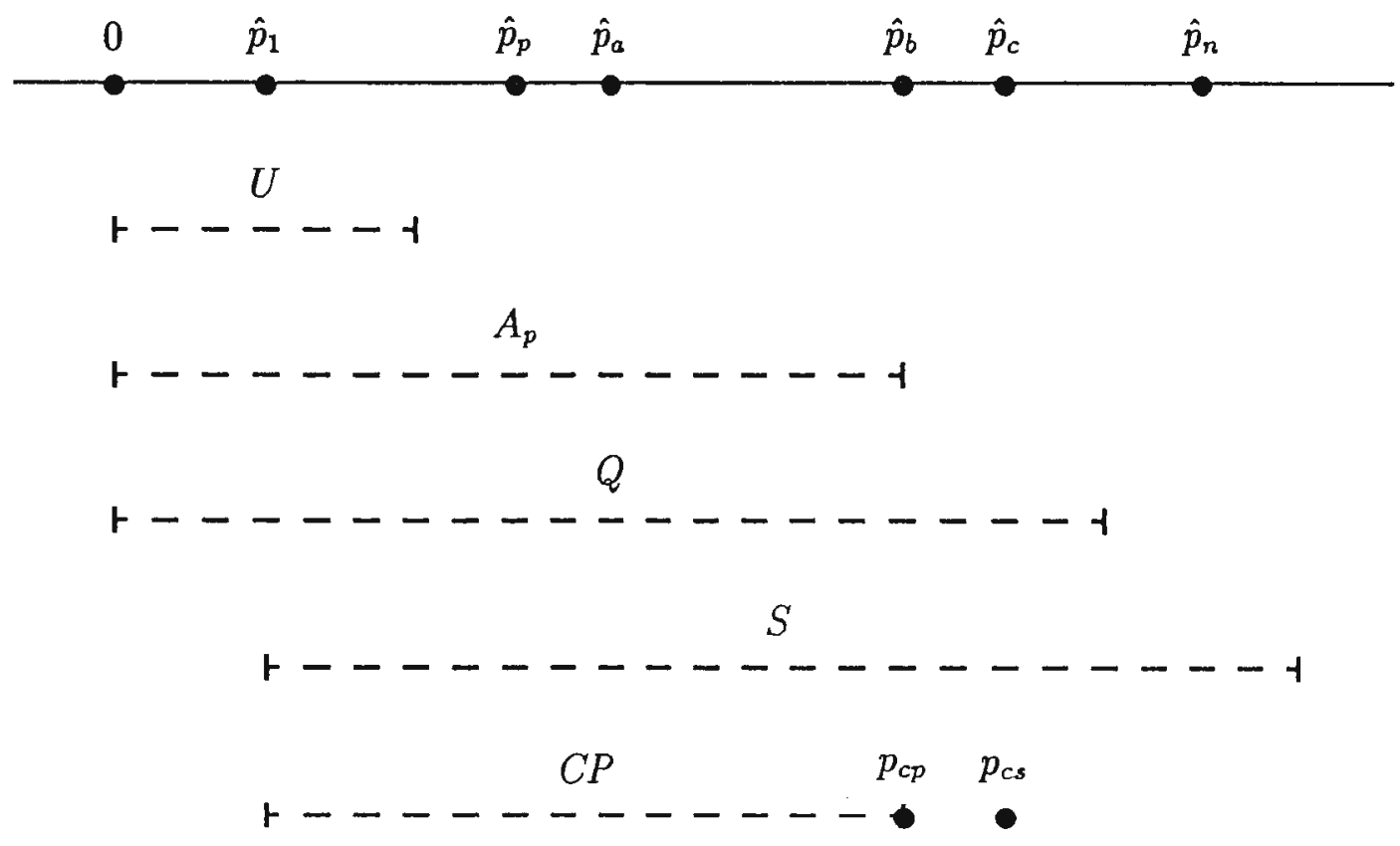


The Commission makes the proposal $P R_{c} \in C P$ that is closest to its ideal policy. This proposal is not amended, becomes the common position, is either approved by the Parliament or confirmed by the Council, and becomes the EC policy $p_{c p}$ under the cooperation procedure. In Figure 5 the Commission does not propose its ideal policy because the Parliament and country 1 prefer the status quo. Instead the Commission proposes the policy that makes the Parliament indifferent to the status quo. This policy is preferred to the status quo by a qualified majority in the Council, by the Parliament and by the Commission. In general, it is possible however that the equilibrium policy is not preferred to the status quo by the Commission or by the Parliament. There are two possible minimal winning coalitions for adoption of legislation under the cooperation procedure, as shown in Table 2: (1) the Commission, the Parliament and a qualified majority in the Council, and (2) all countries. As compared to the consultation procedure approval by the Parliament is now needed if all countries do not prefer the proposal to the status quo.

Figure 6 shows the equilibrium policy as a function of the location of the status quo relative to the ideal policies. Six intervals can be distinguished for the equilibrium. The intervals IV, V and VI are the same as the intervals III, IV and V in Figure 4. In interval III the status quo prevails. The Commission and a qualified majority in the Council want to move to the right but the Parliament does not want that. Moreover, there is no unanimity in the Council for such a move. Interval II, [2 $\hat{p}_{p}-\hat{p}_{c}, \hat{p}_{p}$ ), is similar to interval II in Figure 4. The Commission exercises agenda-setting powers without however obtaining its ideal policy. A qualified majority in the Council, the Commission and the Parliament all want to move to the right but EC policy is not moved further than the policy that makes the Parliament indifferent to the status quo. In interval I the Commission obtains its ideal policy. ${ }^{22}$

\footnotetext{
${ }^{22}$ Depending on the location of the Parliament's ideal policy relative to the configuration of ideal policies of the pivotal countries and the Commission shown in Figure 6, four other situations are
} 
Figure 6: Equilibrium Policy under the Cooperation Procedure.

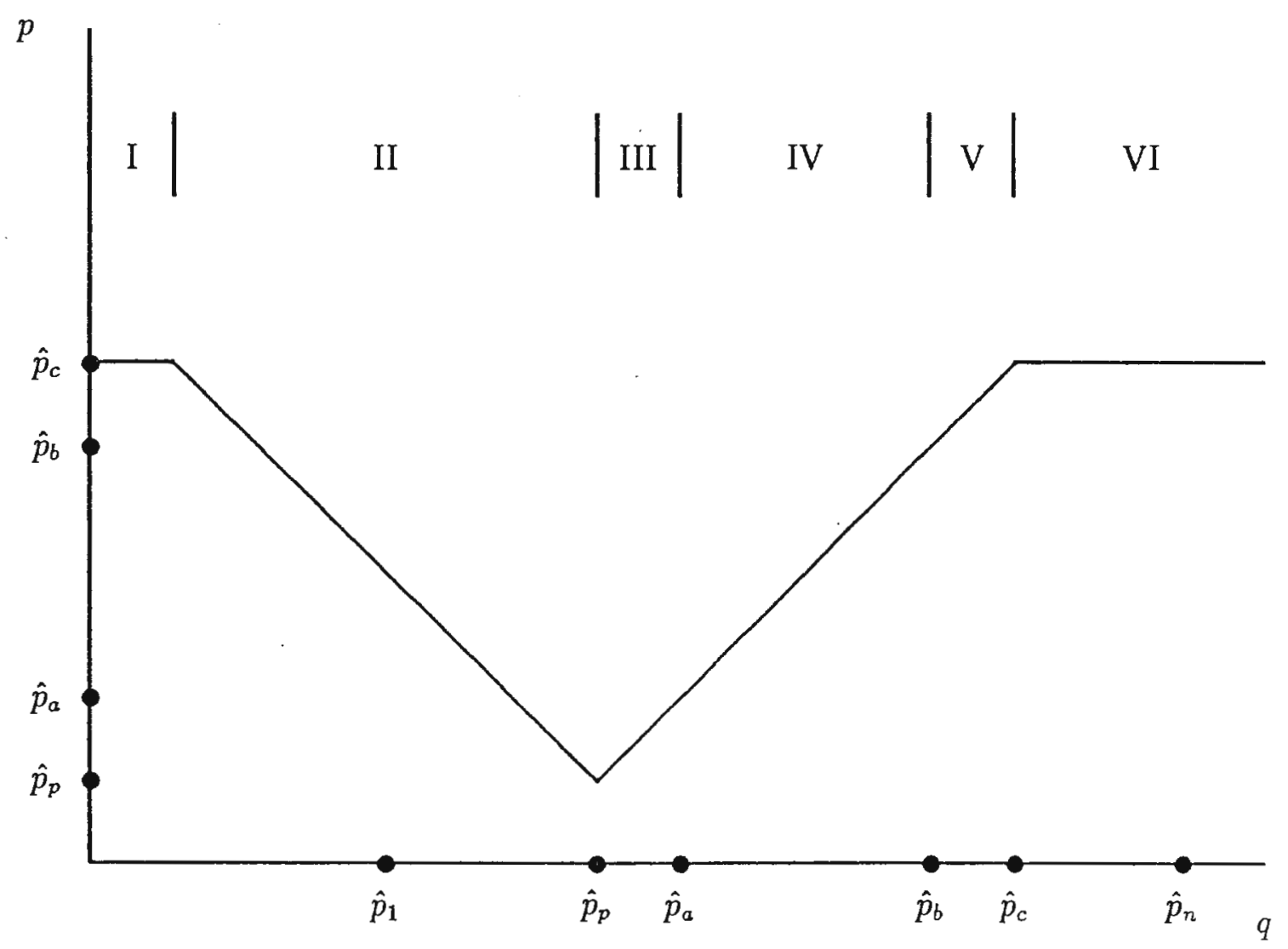




\subsection{A Parliament Amendment}

In the derivation of the equilibrium I disregarded the Parliament's right to amend the common position. I now show that the equilibrium policy is not affected by this assumption.

As explained in the introduction, a common position that was amended by the Parliament must be reexamined by the Commission, which can accept or reject the amendments. The following steps in the procedure look exactly like the consultation procedure, as illustrated in Figure 1. The reexamined proposal - the common position with the accepted amendments - is sent back to the Council. A qualified majority is required to accept the reexamined proposal, while amendments by the Council require unanimity. There is no further role for the Parliament.

Suppose the equilibrium policy under the consultation procedure is preferred to the status quo either by the Parliament or by all countries. The equilibrium policy under the cooperation procedure is then the same as under the consultation procedure. The Commission makes its optimal proposal $P R_{c}^{*}=p_{c p}=p_{c s}$. This proposal is not possible. (1) The Parliament's ideal policy is to the left of all countries' ideal policies. The Commission then prefers to attract country 1's rather than the Parliament's support, and interval III is $\left[\hat{p}_{1}, \hat{p}_{a}\right)$, interval II is $\left[2 \hat{p}_{1}-\hat{p}_{c}, \hat{p}_{1}\right)$ and interval $I$ is $\left(\infty, 2 \hat{p}_{1}-\hat{p}_{c}\right)$. (2) The Parliament has an ideal policy to the right of country a's ideal policy but to the left of the Commission's ideal policy, i.e. $\hat{p}_{p} \in\left[\hat{p}_{a}, \hat{p}_{c}\right)$. In that case the equilibrium policies are the same as under the consultation procedure. (3) The Parliament's ideal policy is to the right of the Commission's ideal policy but to the left of country $n$ 's ideal policy, i.e. $\hat{p}_{p} \in\left[\hat{p}_{c}, \hat{p}_{n}\right]$. Then there are two differences with the consultation procedure: the status quo prevails in the interval $\left[\hat{p}_{c}, \hat{p}_{p}\right)$ and the Commission has agenda-setting powers in the interval $\left[\hat{p}_{p}, 2 \hat{p}_{p}-\hat{p}_{c}\right)$. (4) The Parliament has an ideal policy to the right of all countries' ideal policies. Then there are also two differences with the consultation procedure: the status quo prevails in the interval $\left[\hat{p}_{c}, \hat{p}_{n}\right)$ and the Commission has agenda-setting powers in the interval $\left[\hat{p}_{n}, 2 \hat{p}_{n}-\hat{p}_{c}\right)$. The equilibrium policies for different locations of the Commission's ideal policy are analogous. 
amended in the Council because all countries do not unanimously prefer any other policy, and it thus becomes the common position. If the Parliament amends the common position the Commission rejects the Parliament amendment because the common position is optimal for the Commission, given that the remaining steps in the procedure are like the consultation procedure. The common position thus becomes EC policy whether or not the Parliament amends it.

Suppose now the equilibrium policy under the consultation procedure is preferred to the status quo neither by the Parliament nor by all countries. Under the cooperation procedure the Commission then proposes an equilibrium policy that is farther away from its ideal policy to obtain the approval of either the Parliament or a unanimous Council. In either case the equilibrium policy under the cooperation procedure is closer to the Parliament's ideal policy. It is between the Commission's ideal policy and the Parliament's ideal policy. There is thus no policy both the Commission and the Parliament prefer to the common position. Hence, the common position is preferred to any amendment either by the Parliament or by the Commission. If it is preferred to the common position by the Parliament, the Commission rejects it. If it is preferred by the Commission, the Parliament does not propose it.

Proposition 3 Under the cooperation procedure the Parliament's opportunity to amend the Council's common position does not affect the equilibrium policy.

\subsection{Discussion}

In this subsection I focus on three issues. Once again, I discuss indecision and the powers of the Commission. In addition, I evaluate the powers of the Parliament.

Under the cooperation procedure the EC's ability to reach decisions is further diminished. There are four situations in which indecision occurs: (1) no qualified majority in the Council agrees on the direction of change, as in interval IV in Figure 6; 
(2) a qualified majority and the Parliament agree, but the Commission and some countries do not agree with the qualified majority, as in interval V in Figure 6; (3) a qualified majority and the Commission agree but the Parliament and some countries do not agree with the qualified majority, as in interval III in Figure 6; (4) a qualified majority agrees, but the Parliament, the Commission and some countries do not agree with the qualified majority. ${ }^{23}$

The additional indecision is caused by the institutional requirement that the equilibrium policy also be approved either by the Parliament or by all countries, combined with the heterogeneity of preferences within the Council and between the Parliament and the other institutions. Although the cooperation procedure is a step towards more supranationalism, indecision increases rather than decreases compared to the consultation procedure. This shows once more that indecision has nothing to do with the intergovernmental character of the Council. With respect to the heterogeneity of preferences it is worth noting that the national governments and the Parliament are elected by the same voters. The causes for the existing heterogeneity, in particular for Parliament being to the left of most national governments, are another fruitful topic for future research.

Although the Commission plays an important role as proposer, its powers decrease as compared to the consultation procedure because of the additional institutional requirements for adoption of legislation. As shown above the set of Commission proposals that can be adopted is a subset of the set of proposals that can be adopted under the consultation procedure. This decrease in power is illustrated in Figure 6. The intervals where the status quo prevails and the intervals where the Commission has agenda-setting power are larger than in Figure 4. The intervals where the Com-

\footnotetext{
${ }^{23}$ The last situation is in fact a combination of situations (2) and (3). It is not presented in Figure 6. It would occur in interval V, for example, if the Parliament's ideal policy were to the right of the Commission's ideal policy.
} 
mission's ideal policy becomes EC policy are smaller than in Figure 4. The claim that the Commission's power is strengthened when it is working together with the Parliament is thus false. The Parliament's right to amend the proposal does not affect the equilibrium policy and hence does not create a possibility for cooperation between the Commission and the Parliament. The Parliament's right to reject the common position reduces the set of proposals that can be adopted.

The Parliament acquires substantial powers under the cooperation procedure. Whereas it plays no significant role under the consultation procedure, it has vetopower under the cooperation procedure. The Council can overturn the Parliament's veto by unanimity but it is unlikely that the Parliament's veto would not be supported by any country. In equilibrium this requires at a minimum that the Parliament has an ideal policy to the left (right) of all countries' ideal policies. The Parliament is not likely to have such extreme preferences. Therefore, its veto-power is likely to be effective. This does not mean that one should expect to observe Parliamentary vetos frequently. In equilibrium the Parliament does not exercise its veto because the Commission proposes a policy the Parliament prefers to the status quo.

The basis of the Parliament's veto-power is its right to reject the Council's common position. As shown above its right to amend the common position does not give it any power. The Parliament does not enjoy agenda-setting power nor can it "put pressure on the Council in an alliance with the Commission."

As mentioned above, the relevant policy dimension is often considered to be a nationalist-supranationalist dimension, and the Parliament and the Commission are then given the same ideal policy. Under these specific assumptions the equilibrium policy is the same as under the consultation procedure. It is the policy the Parliament prefers most among the policies that are preferred to the status quo by a qualified majority and belong to the support of the countries' ideal policies. The Parliament could only obtain a policy that is closer to its ideal policy if a smaller majority were 
required in the Council for approval of a proposal, if the Council were not allowed to amend a proposal, or if the Council were denied any role in the legislative process.

\section{The Assent Procedure}

\subsection{Equilibrium}

The equilibrium under the assent procedure is derived in Appendix C. Proposition 4 characterizes the set of proposals that can be adopted.

Proposition 4 Regardless of the relative locations of the status quo and the ideal policies, the set $A S$ of proposals that can be adopted under the assent procedure is the set of proposals that are preferred to the status quo by all countries and by the Parliament, and that belong to the support $S^{\prime}$ of (1) the countries' ideal policies and (2) the policies that are closest to the countries' ideal policies such that they are preferred to the status quo by the Parliament: $A S=U \cap A_{p} \cap S^{\prime}$.

In Figure 7 policy making under the assent procedure is illustrated using the same configuration of ideal policies as in Figure 3. The set of common positions that are approved by the Parliament in the fifth stage of the procedure is the Parliament's acceptance set $A_{p}$. The set of proposals that become the common position in the fourth stage is the set $U$ of policies that are preferred to the status quo by all countries. However, not all proposals $P R_{c} \in U \cap A_{p}$ become the common position. Consider a proposal that is preferred to the status quo by all countries and by the Parliament but does not belong to the support of the countries' ideal policies, i.e. $P R_{c} \in\left(U \cap A_{p}\right) \backslash S=$ $\left[0, \hat{p}_{1}\right) \cdot{ }^{\mathbf{2 4}}$ All countries and the Parliament prefer a policy to the right of it. Therefore, it is amended in the second stage of the procedure. In general, however, a proposal

\footnotetext{
${ }^{24}$ In Figure 7 the Parliament prefers at least one country's ideal policy to the status quo. The policies that are closest to the countries' ideal policies such that they are preferred to the status quo
} 
Figure 7: Policy Making under the Assent Procedure.

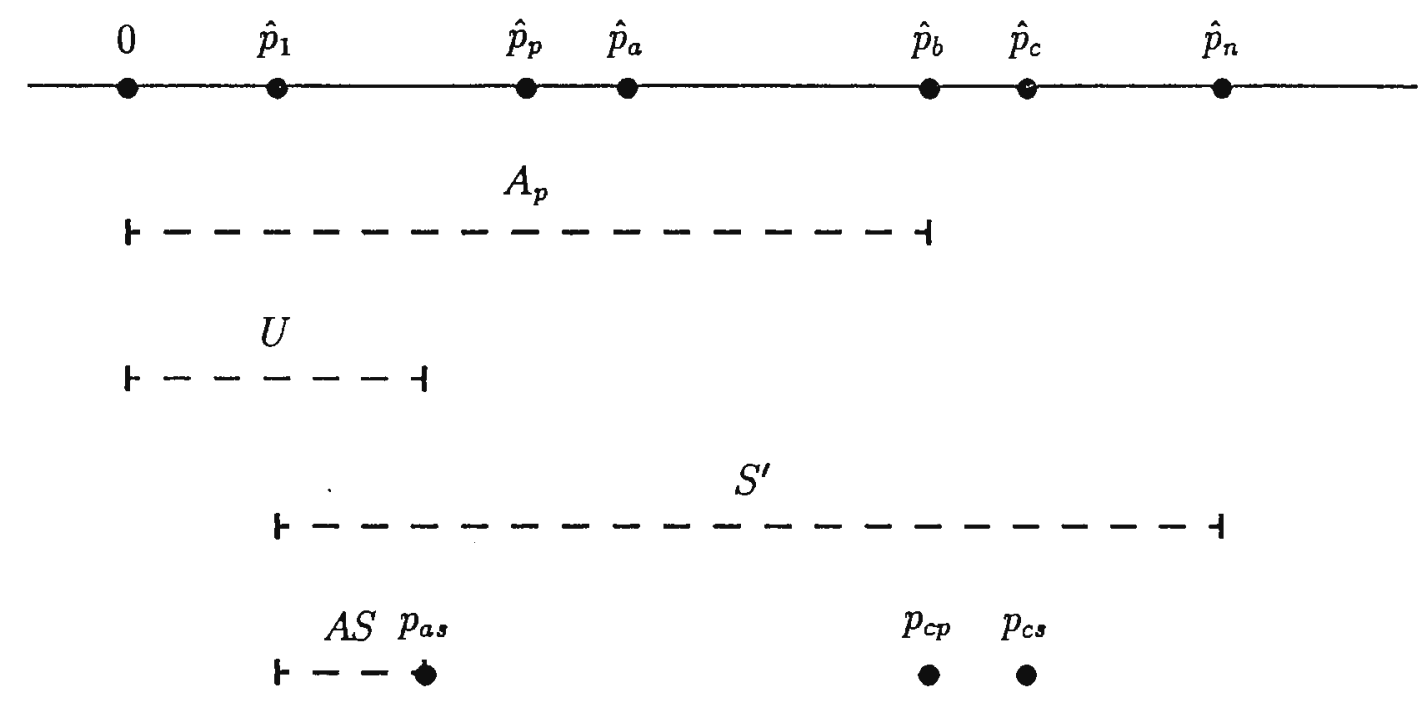

that can be adopted does not necessarily belong to the support $S$ of the countries' ideal policies. Suppose the policy that makes the Parliament indifferent to the status quo is to the left of all countries' ideal policies, i.e. $2 \hat{p}_{p}<\hat{p}_{1}$. In that case EC policy does not belong to the support of the countries' ideal policies because the Parliament prefers the status quo to any such policy, i.e. $A_{p} \cap S=\emptyset$. The policy that makes the Parliament indifferent to the status quo is then the policy that is closest to each country's ideal policy such that it is preferred to the status quo by the Parliament. This policy is not amended in the second stage because the Parliament prefers the status quo to any policy to the right of it. Only a proposal that is preferred to the status quo by all countries and by the Parliament and that belongs to the set $S^{\prime}$ can thus be adopted.

by the Parliament then belong to the support $S$ of the countries' ideal policies. Thus, the set $S^{\prime}$ is equal to the set $S$. 
The Commission makes the proposal $P R_{c} \in A S$ that is closest to its ideal policy: This proposal is not amended, it becomes the common position and is approved by the Parliament. In Figure 7 the Commission does not propose the policy that makes the Parliament indifferent to the status quo, as under the cooperation procedure, because country 1 prefers the status quo to this policy. Instead the Commission proposes the policy that makes country 1 indifferent to the status quo. This policy is preferred to the status quo by all countries, by the Parliament and by the Commission. In general, it is possible, however, that the equilibrium policy is not preferred to the status quo by the Commission. The minimal winning coalition for adoption of legislation under the assent procedure consists only of the Parliament and all countries, as shown in Table 2.

Figure 8 shows the equilibrium policy as a function of the location of the status quo relative to the ideal policies. Five intervals can be distinguished for the equilibrium. In interval III the status quo prevails because the Council does not unanimously prefer any policy to the status quo. In intervals II and IV the Commission exercises agenda-setting powers. In intervals I and $\mathrm{V}$ the Commission obtains its ideal policy. ${ }^{2.5}$

\subsection{Discussion}

Under the assent procedure the EC's ability to reach decisions is still further diminished. There are two situations in which indecision occurs: (1) the Council does not unanimously agree on the direction of change, as in interval III in Figure 8; and (2) the Council agrees unanimously but the Parliament does not agree with the Council. The additional indecision as compared to the cooperation procedure is caused by (1) the use of the unanimity rule in the Council instead of the qualified majority rule, (2) the requirement that the Parliament approve EC policy even though the Council

\footnotetext{
${ }^{25}$ The equilibrium policies for other configurations of ideal policies are analogous.
} 
Figure 8: Equilibrium Policy under the Assent Procedure.

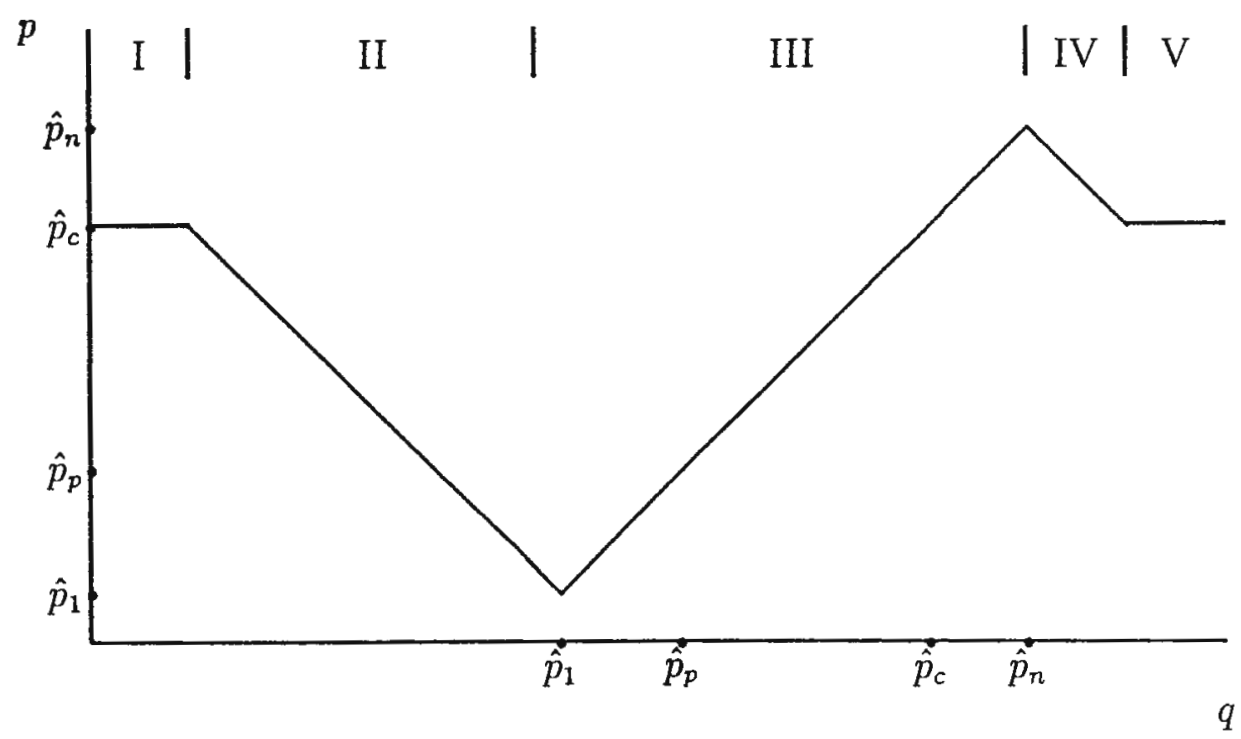


unanimously prefers it to the status quo, and (3) the heterogeneity of preferences.

As compared to the cooperation procedure the first institutional requirement is a step towards pure intergovernmentalism, whereas the second requirement is a step towards more supranationalism. Since under the cooperation procedure a veto by the Parliament is likely to be supported by at least one country, as seen above, the second institutional requirement is not likely to affect the equilibrium policy and to cause more indecision.

The first requirement reduces the powers of the Commission. As illustrated in Figure 8 , the intervals where the status quo prevails and the intervals where the Commission has agenda-setting power are larger than in Figure 6. The intervals where the Commission's ideal policy becomes EC policy are smaller than in Figure 6. The reduction in the Commission's powers and the increase in the Parliament's powers as a result of the second requirement are insignificant for the reasons mentioned above.

\section{Conclusions}

The spatial theory of the principal legislative procedures in the EC provides a framework for assessing some of the supranationalists' and intergovernmentalists' arguments about the EC institutions and institutional change.

Indecision is an important characteristic of all three legislative procedures considered. It is, however, not caused by the intergovernmental nature of the principal legislative body, contrary to the supranationalists' claims. It results from the institutional requirements for adoption of legislation, combined with the heterogeneity of countries' and institutions' preferences. In particular, the institutional requirements that cause indecision are: (1) the Council's qualified majority rule for approval of Commission proposals, under the consultation and cooperation procedures; (2) the Council's unanimity rule for approval of amendments to the Commission proposal, 
under all three procedures; (3) the Parliament's veto in the absence of unanimity in the Council, under the cooperation procedure; (4) the Parliament's veto, under the assent procedure; and (5) the Council's unanimity rule for approval of Commission proposals, under the assent procedure. Introduction of simple majority rule in the Council would thus reduce indecision without a transfer of power to a supranational body. Moreover, the greater involvement of the Parliament in the new procedures, a step towards more supranationalism, leads to more indecision.

The Commission has considerable powers under all three procedures. As monopoly proposer the Commission can choose the policy it prefers most among the policies that will be adopted given the locations of the ideal policies and the status quo. These powers, however, do not result from the supranational character of the Commission, as claimed by intergovernmentalists. Like the indecision, the Commission's powers result from the institutional requirements for adoption of legislation combined with the heterogeneity of preferences. In particular, these institutional requirements are the qualified majority and unanimity rules in the Council. Any other proposer with the same preferences, whether a supranational institution or a country, would have the same powers given the institutional requirements. Concerning the Commission's preferences it should be noted that the Commission is appointed by a unanimous Council. The key to eliminating the proposer's power is the introduction of simple majority rule in the Council, for approval of Commission proposals as well as for amendments. This represents a move away from rather than towards pure intergovernmentalism. Moreover, the new procedures, a step towards more supranationalism, reduce the powers of the Commission.

The Parliament, which is usually portrayed as powerless, has acquired veto-power under the new procedures. Under the cooperation procedure a Parliamentary veto can be overturned by a unanimous Council but it is unlikely that no country supports a Parliamentary veto. The Parliament's opportunity to amend the Commission pro- 
posal under the cooperation procedure, however, does not increase the Parliament's powers.

\section{Appendix}

\section{A The Consultation Procedure}

Suppose no amendment is offered or the amendment is defeated. In the final stage of the procedure as shown in Figure 1, the Council then compares the Commission proposal $P R_{c}$ to the status quo of zero. To defeat the status quo the proposal needs the support of a qualified majority.

If country $a$ has a positive ideal policy, the set $Q$ of proposals that are preferred to the status quo by a qualified majority is country a's acceptance set $A_{a}$, as in Figure 3. If the proposal belongs to this set it is adopted in the final stage. Otherwise the status quo prevails. If country $b$ has a negative ideal policy the derivation of the equilibrium is analogous. If country $a$ has a negative ideal policy and country $b$ has a positive ideal policy no policy is preferred to the status quo by a qualified majority. Any proposal is then defeated in the final stage, and any amendment is defeated in the third stage. ${ }^{26}$ No amendment is therefore offered and no proposal is made by the Commission. As a result the status quo prevails. Therefore I focus on the case in which country $a$ prefers a positive policy.

Suppose the proposal does not defeat the status quo in the final stage, i.e. $P R_{c} \notin$ $Q$. In the third stage the countries then compare the amendment $A P_{1}$-if an amendment was offered - to the status quo. The amendment needs the support of all coun-

\footnotetext{
${ }^{26}$ More precisely, no policy other than the status quo is weakly preferred to the status quo by a qualified majority. Any proposal and any amendment other than the status quo are defeated. The set $Q$ is equal to the singleton $\{0\}$.
} 
tries to be accepted. There are two cases. First, if country 1 prefers a negative policy, no amendment can obtain unanimous support because country $a$ prefers a positive policy. Since no amendment is accepted in the third stage, none is offered in the second stage and the status quo prevails. Second, if country 1 prefers a positive policy, as in Figure 3, the set $U$ of policies that are preferred to the status quo by all countries is country l's acceptance set $A_{1}$, since country 1 is pivotal under the unanimity rule. If the amendment belongs to this set, it is accepted. In the second stage country 1 then proposes its ideal policy as an amendment. This amendment is accepted and becomes EC policy.

Suppose next that the proposal defeats the status quo in the final stage, i.e. $P R_{c} \in Q$. In the third stage the countries then compare the amendment to the proposal. Country $i$ supports the amendment if the amendment is closer to its ideal policy than the proposal. In particular, if the proposal is to the left of its ideal policy, it supports the amendment if $A P_{1} \in\left[P R_{c}, 2 \hat{p}_{i}-P R_{c}\right]$. As a consequence, no amendment is accepted if the proposal belongs to the support $S=\left[\hat{p}_{1}, \hat{p}_{n}\right]$ of the countries' ideal policies. Since no amendment is accepted, none is offered and the Commission proposal becomes EC policy. This is illustrated in Figure 3. A proposal $P R_{c} \in Q \cap S=C S$ thus is not amended in the second stage, and it defeats the status quo in the final stage and is implemented.

If the proposal is to the left of all countries' ideal policies, as a proposal $P R_{c} \in$ $Q \backslash S=\left[0, \hat{p}_{1}\right)$ in Figure 3 , country 1 proposes its ideal policy as an amendment. The amendment is then accepted and becomes EC policy. If the proposal is right of all countries' ideal policies and all countries prefer country 1's ideal policy to the proposal, country 1 also proposes its ideal policy as an amendment and again it is implemented. If the proposal is to the right of all countries' ideal policies but country $n$ does not prefer country 1's ideal policy to the proposal, then country 1 proposes the policy closest to its ideal policy such that country $n$ prefers it to the proposal, 
i.e. $2 \hat{p}_{n}-P R_{c}$. This amendment is accepted and becomes EC policy.

Depending on the relative locations of the status quo, the ideal policies, and the Commission proposal, one can thus distinguish the following six disjoint cases. (1) $P R_{c} \notin Q$ and $\hat{p}_{1} \leq 0$. The Commission proposal is not preferred to the status quo by a qualified majority, and the Council does not unanimously prefer any policy to the status quo. Then the status quo prevails. (2) $P R_{c} \notin Q$ and $0<\hat{p}_{1}$. The Commission proposal is not preferred to the status quo by a qualified majority but there are policies the Council unanimously prefers to the status quo. In this case country 1's ideal policy becomes EC policy. (3) $P R_{c} \in C S=Q \cap S$. The Commission proposal is preferred to the status quo by a qualified majority and belongs to the support of the countries' ideal policies. The proposal is then adopted. (4) $P R_{c} \in Q \backslash S$ and $P R_{c}<\hat{p}_{1}$. The Commission proposal is preferred to the status quo by a qualified majority but is to the left of country 1's ideal policy. Country 1's ideal policy then becomes EC policy. (5) $P R_{c} \in Q \backslash S, \hat{p}_{n}<P R_{c}$ and $2 \hat{p}_{n}-P R_{c} \leq \hat{p}_{1}$. The Commission proposal is preferred to the status quo by a qualified majority but is to the right of country $n$ 's ideal policy; country $n$ prefers country 1's ideal policy to the proposal. Again, country 1's ideal policy becomes EC policy. (6) $P R_{c} \in Q \backslash S, \hat{p}_{n}<P R_{c}$ and $\hat{p}_{1}<2 \hat{p}_{n}-P R_{c}$. The Commission proposal is preferred to the status quo by a qualified majority but is to the right of country $n$ 's ideal policy, and country $n$ does not prefer country 1 's ideal policy to the proposal. Then the policy that makes country $n$ indifferent to the status quo becomes EC policy. In general, a proposal $P R_{c} \in C S$ is adopted, as in case 3 , whereas other proposals are defeated, as in case 1 , or amended, as in cases 2, 4 and $5 .{ }^{27}$ The set $C S$ is thus the set of proposals that can be adopted under the consultation procedure.

\footnotetext{
${ }^{27}$ Note that if country $a$ prefers a negative policy and country $b$ prefers a positive policy the set $C S$ is equal to the singleton $\{0\}$. As mentioned above, the status quo prevails, so the above statement holds in this case as well.
} 
to its acceptance set $A_{p}$. The common position thus becomes EC policy if either the Parliament or a unanimous Council approve it.

Suppose country 1 did not propose an amendment or its amendment was defeated. In the fourth stage of the procedure as shown in Figure 2 countries then vote on the original Commission proposal. If the proposal is approved by a qualified majority it becomes the common position, otherwise the status quo prevails. The Council compares the Commission proposal $P R_{c}$ to the status quo. ${ }^{32}$ The countries' optimal voting strategies are thus the same as in the final stage of the consultation procedure. The set of proposals that become the common position is the set $Q$ of proposals that are preferred to the status quo by a qualified majority. As under the consultation procedure I focus on the case in which a qualified majority has a positive ideal policy, i.e. $\hat{p}_{a}>0$.

Suppose the proposal does not become the common position in the fourth stage, or it is defeated in Parliament and not confirmed by a unanimous Council, i.e. $P R_{c} \notin$ $Q \cap\left(A_{p} \cup U\right)$. In the third stage the countries then compare the amendment $A P_{1}-$ if an amendment was offered - to the status quo. ${ }^{33}$ The countries' voting strategies on the amendment are then the same as in the third stage of the consultation procedure. The set of amendments that are accepted is thus the set $U$ of policies that are preferred

\footnotetext{
${ }^{32}$ In fact, the Council compares to the status quo the policy that is implemented if it approves the proposal. This policy is not necessarily equal to the proposal. If the Parliament nor a unanimous Council prefer the proposal to the status quo, it is the status quo and the countries are indifferent. I assume countries then vote sincerely. Therefore it can be said that the Council compares the proposal to the status quo. This assumption does not affect the equilibrium policy.

${ }^{33}$ In fact, the countries compare to the status quo the policy that is implemented if the amendment is approved. This policy is not necessarily equal to the amendment. If the Parliament nor a unanimous Council prefer the amendment to the status quo, it is the status quo and the countries are indifferent. I assume countries then vote sincerely. Therefore it can be said that the countries compare the amendment to the status quo. This assumption does not affect the equilibrium policy.
} 
to the status quo by all countries. Country 1's amendment strategy is then also the same as under the consultation procedure. It proposes its own ideal policy if all countries prefer a positive policy. This amendment becomes the common position. If the Parliament does not approve it, it is confirmed by the Council. In any case it becomes EC policy. If country 1 prefers a negative policy, it does not propose an amendment and the status quo prevails.

Suppose now the proposal becomes the common position, and it is not defeated in Parliament or it is confirmed by the Council, i.e. $P R_{c} \in Q \cap\left(A_{p} \cup U\right)$. In the third stage the countries then compare the amendment to the proposal. The countries' voting strategies on the amendment are again the same as in the third stage of the consultation procedure. If the proposal belongs to the support $S$ of the countries' ideal policies, no amendment is accepted. Therefore no amendment is offered and the Commission proposal becomes EC policy. This is illustrated in Figure 5. A proposal $P R_{c} \in Q \cap\left(A_{p} \cup U\right) \cap S=C S \cap\left(A_{p} \cup U\right)=C P$ is not amended in the second stage, it becomes the common position and is approved by the Parliament.

If the proposal does not belong to the support $S$ of the countries' ideal policies, country 1's amendment strategy is again the same as under the consultation procedure. If all countries prefer country 1's ideal policy to the proposal, it proposes its ideal policy. Otherwise it proposes the policy that makes country $n$ indifferent to the status quo. The amendment becomes the common position. It is approved by the Parliament or confirmed by the Council and thus becomes EC policy.

Depending on the relative locations of the status quo, the ideal policies and the Commission proposal, one can thus distinguish six cases similar to the six cases under the consultation procedure. ${ }^{34}$ In general, a proposal $P R_{c} \in C P$ is adopted, whereas other proposals are defeated or amended. The set $C P$ is thus the set of proposals

\footnotetext{
${ }^{34}$ One only needs to substitute $Q \cap\left(A_{p} \cup U\right)$ for $Q$ to obtain the six cases under the cooperation procedure from the six cases under the consultation procedures.
} 
that can be adopted under the consultation procedure.

Moreover, whether or not the Commission makes a proposal that is preferred to the status quo either by a qualified majority in the Council and by the Parliament or by all countries, and that belongs to the support of the countries' ideal policies, the policy $p_{c p}$ that is implemented under the cooperation procedure satisfies these conditions. ${ }^{35}$ Therefore, the Commission makes the proposal $P R_{c} \in C P$ that is closest to its ideal policy. The optimal proposal $P R_{c}^{*}$ is not amended, it becomes the common position and is either approved by the Parliament or confirmed by the Council.

\section{The Assent Procedure}

The assent procedure is like the cooperation procedure as depicted in Figure 2 but (1) the Council cannot confirm its common position in a final stage and (2) unanimity in the Council is required to adopt a common position in the fourth stage. In the last stage of the assent procedure the Parliament approves the common position if it belongs to its acceptance set $A_{p}$. The set of proposals that become the common position in the fourth stage of the procedure is the set $U$ of proposals that are preferred to the status quo by all countries. I focus on the case in which the Parliament and all countries have positive ideal policies, as in Figure 7. The set $U$ is then country 1's acceptance set $A_{1}$. If the Parliament and all countries have negative ideal policies the derivation of the equilibrium is analogous. In other cases no proposal becomes EC policy, and no amendment is accepted by all countries and subsequently approved by

\footnotetext{
${ }^{35}$ The implemented policy is preferred to the status quo by a qualified majority and belongs to the support of the countries' ideal policies for the same reasons as under the consultation procedure. Moreover it is preferred to the status quo by the Parliament or by all countries in all six cases: (1) $p_{c p}=0 \in A_{p} ;(2)$, (4) and (5) $p_{c p}=\hat{p}_{1} \in U ;$ (3) $p_{c p}=P R_{c} \in C P ;$ and (6) $0<p_{c p}=2 \hat{p}_{n}-P R_{c}<$ $\hat{p}_{n} \in A_{p} \cup U \Rightarrow p_{c p} \in A_{p} \cup U$.
} 
the Parliament. No amendment is therefore offered and no proposal is made. As a result the status quo prevails.

Suppose the proposal does not become the common position or it is defeated in Parliament, i.e. $P R_{c} \notin U \cap A_{p}$. In the third stage the countries then compare the amendment $A P_{1}$-if an amendment was offered-to the status quo. An amendment that is preferred to the status quo by all countries thus becomes the common position. The common position needs approval by the Parliament to become EC policy. Hence, the set of amendments that can become EC policy is the set of amendments that are preferred to the status quo by all countries and by the Parliament, i.e. $U \cap A_{p}$. If the Parliament prefers country 1's ideal policy to the status quo, as in Figure 7, country 1 proposes its ideal policy as amendment. If the Parliament prefers the status quo to country 1's ideal policy, country 1 proposes the policy that makes the Parliament indifferent to the status quo, i.e. $2 \hat{p}_{p}$. In both cases the amendment is accepted by all countries, approved by the Parliament and becomes EC policy.

Suppose now the proposal becomes the common position and is approved by the Parliament, i.e. $P R_{c} \in U \cap A_{p}$. If the Parliament prefers the status quo to the amendment - if an amendment was offered - the countries compare the status quo to the proposal in the third stage. Since all countries prefer the proposal to the status quo, all countries then vote against the amendment. Therefore, no such amendment is offered, and the Commission proposal becomes EC policy.

Suppose the Parliament prefers the amendment to the status quo. If the proposal belongs to the support $S$ of the countries' ideal policies, no amendment is then accepted. Therefore no amendment is offered and the Commission proposal becomes EC policy. If the proposal is the policy that makes the Parliament indifferent to the status quo and this policy is to the left of all countries' ideal policies, then no amendment is accepted either. In general, let $S^{\prime}$ denote the support of (1) the countries' ideal policies and (2) the policies that are closest to the countries' ideal 
policies such that they are preferred to the status quo by the Parliament: i.e., $S^{\prime}=$ $\left[\min \left\{\hat{p}_{1}, \max \left\{0,2 \hat{p}_{p}\right\}\right\}, \max \left\{\hat{p}_{n}, \min \left\{0,2 \hat{p}_{p}\right\}\right\}\right]$. A proposal $P R_{c} \in U \cap A_{p} \cap S^{\prime}=A S$ is not amended, becomes the common position, is approved by the Parliament and becomes EC policy. In Figure 7 the Parliament prefers at least one country's ideal policy to the status quo. The set $S^{\prime}$ is then equal to the support $S$ of the countries' ideal policies and $A S=U \cap A_{p} \cap S .^{36}$

Country 1 proposes its ideal policy as an amendment, if (1) the proposal is to the left of all countries' ideal policies and the Parliament prefer(s) country 1's ideal policy to the status quo, and if (2) if the proposal is to the right of all countries' ideal policies and all countries prefer country 1's ideal policy to the proposal. If the Parliament prefers the status quo to country l's ideal policy and the proposal is to the left of the policy $2 \hat{p}_{p}$ that makes the Parliament indifferent to the status quo, then country 1 proposes the policy $2 \hat{p}_{p}$. If the proposal is to the right of all countries' ideal policies but country $n$ does not prefer country 1's ideal policy to the proposal, then country 1 proposes the policy that makes country $n$ indifferent to the proposal, i.e. $2 \hat{p}_{n}-P R_{c}$. In each case the amendment is accepted and becomes EC policy.

In general, a proposal $P R_{c} \in A S$ is adopted, whereas other proposals are defeated or amended. The set $A S$ is thus the set of proposals that can be adopted under the consultation procedure.

Moreover, whether or not the Commission makes a proposal that is preferred to the status quo by the Parliament and by all countries, and that belongs to the set $S^{\prime}$, the policy $p_{a s}$ that is implemented under the assent procedure satisfies these

\footnotetext{
${ }^{36}$ If any policy the Parliament prefers to the status quo is left of all countries' ideal policies, then the set $A S$ is the singleton of the most rightist policy the Parliament prefers to the status quo, i.e. $A S=\max \left\{0,2 \hat{p}_{p}\right\}$. If any policy the Parliament prefers to the status quo is right of all countries' ideal policies, then the set $A S$ is the singleton of the most leftist policy the Parliament prefers to the status quo, i.e. $A S=\min \left\{0,2 \hat{p}_{p}\right\}$.
} 
conditions. Therefore, the Commission makes the proposal $P R_{c} \in A S$ that is closest to its ideal policy. The optimal proposal $P R_{c}^{*}$ is not amended, it becomes the common position and is approved by the Parliament.

\section{References}

Bieber, Roland. 1988. "Legislative Procedure for the Establishment of the Single Market." Common Market Law Review 25: 711-24.

Bieber, R., Pantalis, J. and J. Schoo. 1986. "Implications of the Single Act for the European Parliament." Common Market Law Review 23: 767-92.

Black, Duncan. 1958. The Theory of Committees and Elections. London: Cambridge University Press.

Bogdanor, Vernon. 1989. "The June 1989 European Elections and the Institutions of the European Community." Government and Opposition 24: 199-214.

Corbet, Richard. 1989. "Testing the New Procedures: The European Parliament's First Experiences with its New 'Single Act' Powers." Journal of Common Market Studies 4: 359:72.

Crombez, Christophe. 1994. "Maastricht and the Co-Decision Procedure." Working Paper. Stanford University.

Curtin, Deirdre. 1993. "The Constitutional Structure of the Union: A Europe of Bits and Pieces." Common Market Law Review 30: 17-69.

Edward, David. 1987. "The Impact of the Single Act on the Institutions." Common Market Law Review 24: 19-30.

Fitzmaurice, John. 1988. “An Analysis of the European Community's Co-operation Procedure." Journal of Common Market Studies 4: 389:400.

Garrett, Geoffrey. 1992. "International Cooperation and Institutional Choice: The European Community's Internal Market.” International Organization 46: 533-60. 
Krehbiel, Keith. 1988. "Spatial Models of Legislative Choice." Legislative Studies Quarterly 13: 259-319.

Krehbiel, Keith. 1993. "A Theory of Divided and Unified Government." Research Paper No. 1270. Graduate School of Business, Stanford University.

Lasok, Dominik. 1991. Law and Institutions of the European Communities. London: Butterworths.

Laver, Michael and W. Ben Hunt. 1992. Policy and Party Competition. New York: Routledge, Chapman and Hall.

Lenaerts, Koen. 1991. "Some Reflections on the Separation of Powers in the European Community." Common Market Law Review 28: 11-35.

Nugent, Neil. 1991. The Government and Politics of the European Community. Durham: Duke University Press.

Peters, B. Guy. 1992. "Bureaucratic Politics and the Institutions of the European Community." in A. Sbragia (ed) Euro-Politics. Washington D.C.: Brookings.

Romer, Thomas and Howard Rosenthal. 1978. "Political Resource Allocation, Controlled Agendas, and the Status Quo." Public Choice 33: 27-43.

Treaties establishing the European Communities. 1987. Luxembourg: Office for Official Publications of the European Communities.

Treaty on European Union. 1992. Luxembourg: Office for Official Publications of the European Communities.

Tsebelis, George. 1992. "The Power of the European Parliament as a Conditional Agenda Setter." American Political Science Review Forthcoming. 